\title{
Structure and dynamics of irregular multiarm star polymers
}

\author{
D.Vlassopoulos ${ }^{1}$, T.Pakula ${ }^{2}$, J.Roovers ${ }^{3}$ \\ 1 Foundation for Research and Technology-Hellas (FO.R.T.H.) \\ Institute of Electronic Structure and Laser, \\ 71110 Heraklion, Crete, Greece \\ 2 Max-Planck Institute for Polymer Research, \\ Postfach 3148, 55021 Mainz, Germany \\ 3 National Research Council, \\ Institute for Chemical Process and Environmental Technology, Ottawa, \\ Ontario K1A0R6, Canada
}

\section{Received October 1, 2001}

\begin{abstract}
Melt properties of highly branched star polymers consisting of a 1,2-polybutadiene core and nearly 270 arms of 1,4-polybutadiene with varying sizes have been investigated using small angle X-ray scattering (SAXS) and dynamic rheological measurements in the linear viscoelastic limit. Despite their difference in internal structure compared to the regular stars with 128 arms and spherical dendritic core, these polymers exhibit the same features: a liquid-like ordering resulting from their specific intramolecular monomer density distribution. This leads to a dual terminal viscoelastic relaxation, consisting of a fast arm relaxation and a slow structural relaxation mechanisms. Both modes conform quantitatively to the generic behaviour of multiarm star polymers, suggesting a universality of the behaviour of highly branched macromolecular objects.
\end{abstract}

Key words: star polymers, structure, rheology, linear viscoelasticity, relxation processes, dynamics

PACS: $61.25 . \mathrm{Hq}$, 83.10.Nn, 81.05. Lg

\section{Introduction}

Star polymers with a high number of arms (functionality) and a spherical core, thereafter called "regular" multiarm stars (see figure 1) are a class of architecturally complex soft materials with properties that can be regarded as intermediate between those characteristic for polymers (the individual arms) and those characteristic for colloids (with a compact spherical shape) [1-4]. This can be rationalized by considering, that, on the one hand the polymers (a contiguous sequence of $N$ covalently bonded monomers) are characterized by weak interactions at monomeric scales, of 

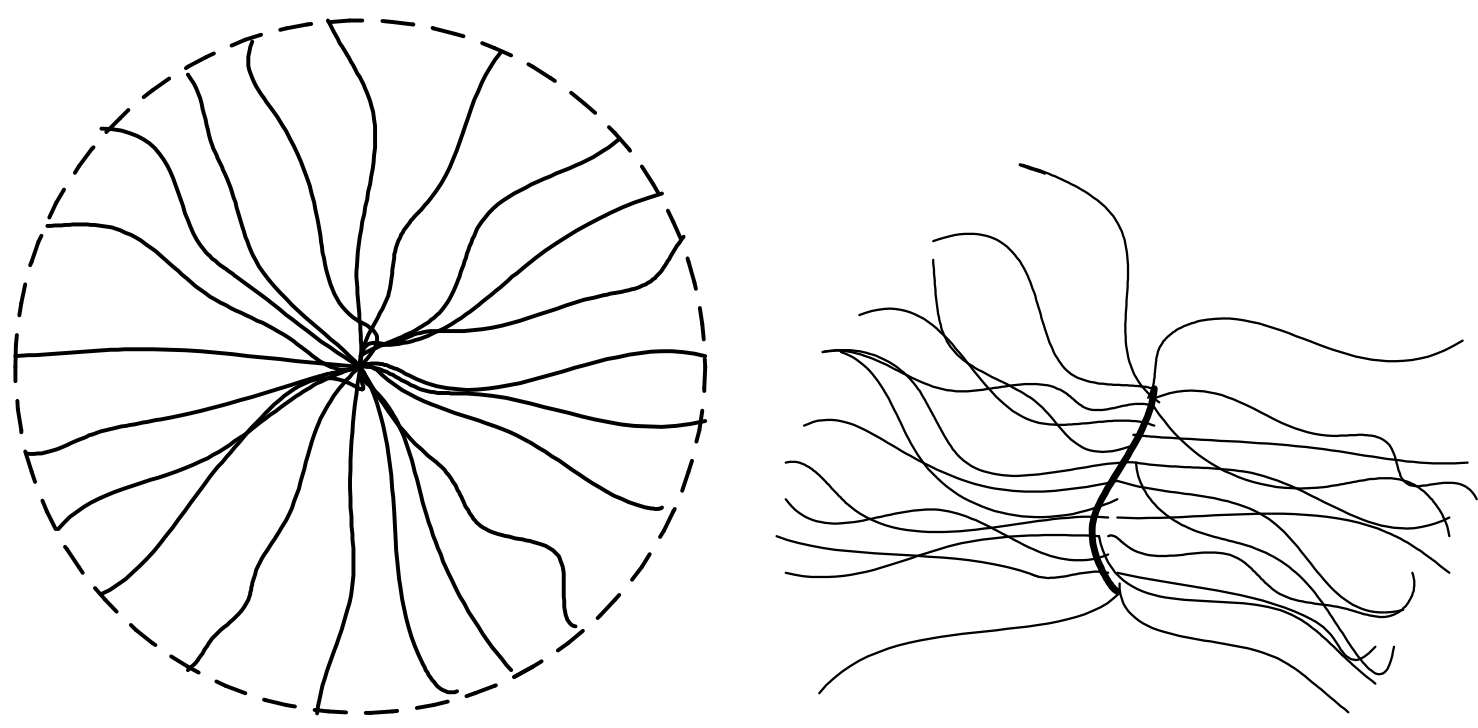

Figure 1. Schemes of molecular structures of regular (left) and irregular (right) multiarm star polymers.

$O\left(k_{\mathrm{B}} T\right)$ or less, and by a relevant correlation length $\xi_{c}$ of $O(n m)$ independent of $N$. Consequently, very high concentrations are needed in order to reach short range ordering, if attainable at all. On the other hand, colloidal dispersions of solid particles with the radius $R_{0}$ in a host fluid, exhibit a size-dependent dynamic behaviour with correlation length of $O\left(R_{0}\right)$, with their long-range ordering occurring at relatively low number densities [2]. As a result of this, multiarm star polymers exhibit a very rich behaviour combining both polymeric and colloidal properties, whose relative importance can be tuned at the molecular level by variation of arm size and arm number.

In recent years, we have focused on the systematic study of the ordering and dynamics of regular multiarm star polymers, both in solution and in the melt. These polymers were synthesized anionically using chlorosilane chemistry and are nearly monodisperse [5]. Owing to their topology, they exhibit a specific monomer density distribution. This justifies considering these macromolecules as particles [6] with a core-corona morphology and two characteristic length scales: a small, $\xi_{c}$, which represents the size of a self-avoiding segment (interaction blob) and is of polymeric nature, and a large, $R_{0}$, which represents typically the overall radius of the star and is of colloidal nature [1].

Molecularly dispersed in a good solvent, such regular stars exhibit liquid-like order above their overlap concentration $c^{*}$, as demonstrated by SANS experiments [7]. The reason for their liquid-like structure formation is, in this case, the enhanced osmotic pressure that outbalances the elastic energy of the entropically stretched arms [10]. This type of weak order persists in the melt state as well $[9,10]$, however, as a consequence of excluded volume effects on the macromolecular scale because of the intramolecular monomer density reaching the values of the bulk material [11]. The dynamics in non-dilute solutions revealed the presence of cooperative diffusion (poly- 
Table 1. Molecular characteristics of irregular star polymers $\left(M_{w} / M_{n}<1.1\right)$.

\begin{tabular}{|c|c|c|c|}
\hline Sample & $f$ & $M_{a}(\mathrm{~g} / \mathrm{mol})$ & $T_{g}\left({ }^{\circ} \mathrm{C}\right)$ \\
\hline LS2 & 267 & 4460 & -93 \\
\hline LS3 & 278 & 9300 & -92 \\
\hline LS4 & 267 & 18300 & -91 \\
\hline LS5 & 269 & 29300 & -92 \\
\hline LS6 & 263 & 42300 & -92 \\
\hline
\end{tabular}

meric) and self diffusion and structural relaxation (colloidal) modes [4,12], whereas unusual thermal gelation behaviour was detected as a result of the strong excluded volume interactions [13]. In the melt state, the dynamics was characterized by a two-step terminal viscoelastic relaxation, consisting of a fast mode related to arm relaxation (independent of functionality $f$, but strongly dependent on arm molecular weight, $M_{a}$ ) and of a slow mode attributed to structural relaxation (cooperative rearrangements of stars, strongly dependent on both $f$ and $\left.M_{a}\right)[9,10,14]$.

In this paper, we extend the above work by addressing the effects of internal structural changes of multiarm stars to their structure and dynamic properties in the melt. In particular, we consider multiarm stars with very high functionality $(f \approx 270)$, which, however, have been prepared by anionic means different from the case of regular stars and, as a consequence, have a non-spherical core region. We find that this microstructural difference does not affect their order and rheological characteristics, and, based on these results we suggest that the studied systems belong to the same universality class of highly branched polymers.

\section{Experimental}

\subsection{Materials}

The synthesis of multiarm star polymers with 1,4-polybutadiene arms and a very high functionality (about 270) has been described in detail elsewhere [15]. Briefly, a short 1,2-polybutadiene backbone chain was hydrosilylated with $\mathrm{HSi}\left(\mathrm{CH}_{3}\right) \mathrm{Cl}_{2}$ yielding two coupling sites per monomer unit; the latter were substituted with 1,4-polybutadiene by adding of poly(butadienyl)lithium. Because the yield of the hydrosilylation reaction of the polymer did not exceed $80 \%$, the architecture of the resulting highly branched polymer was such that on average four out of five monomer segments were substituted with a total of eight arms. The reason for naming these stars "irregular" stems from the fact that their arms are not grafted to a truly spherical dendritic core, as in the case of the regular multiarm stars with functionalities of 64 and 128 [5]. Despite this difference, the irregular stars still possess a nearly spherical shape, as revealed by SANS measurements in dilute solution and their comparison to respective data from regular stars [16], but there is certainly a small difference in internal structure (see figure 1). The important molecular characteristics of the irregular stars used in this work are listed in table 1. 


\subsection{Small angle X-ray scattering (SAXS)}

SAXS measurements were conducted using a rotating anode (Rigaku $18 \mathrm{~kW}$ ) $\mathrm{X}$-ray beam with a pinhole collimation and a two-dimensional detector (Siemens) with $512 \times 512$ pixels. A double graphite monochromator for the $\mathrm{Cu} \mathrm{K \alpha}$ radiation $(\lambda=0.154 \mathrm{~nm})$ was used. The beam diameter was about $0.5 \mathrm{~mm}$ and the distance of the sample to the detector was $1.3 \mathrm{~m}$. Measurements were performed at room temperature for samples of about $1 \mathrm{~mm}$ thickness. The recorded scattered intensity distributions were integrated over the azimuthal angle and are presented as functions of the scattering vector ( $s=2 \sin \theta / \lambda$, where $\theta$ is the scattering angle).

\subsection{Dynamic rheology}

Small amplitude oscillatory shear measurements were carried out over a wide temperature range (from about $-100{ }^{\circ} \mathrm{C}$ to $150{ }^{\circ} \mathrm{C}$ ) using a Rheometric Scientific mechanical spectrometer (ARES 2KFRTN1). Parallel plates with 8 and $6 \mathrm{~mm}$ diameter and $1 \mathrm{~mm}$ gap were used, under dry nitrogen atmosphere. The mate$\mathrm{rial} /$ measurement stability and the linear viscoelastic regime were confirmed via dynamic time sweep and dynamic strain sweep tests at different frequencies and temperatures. Frequency dependencies of $G^{\prime}$ and $G^{\prime \prime}$ measured within the frequency range $0.01-100 \mathrm{rad} / \mathrm{s}$ at various temperatures were used to construct master curves providing $G^{\prime}$ and $G^{\prime \prime}$ data over a very broad range of frequencies. Only shifts along the frequency scale have been performed. This procedure provided a temperature dependence of shift factors $\left(\log a_{T}\right.$ vs. $T$ ). The relaxation times corresponding to the transition to the Newtonian flow range at low frequencies and to the glassy range at high frequencies at the reference temperature have been determined as $\tau\left(T_{\text {ref }}\right)=1 / \omega_{c}$, where $\omega_{c}$ is the frequency at which the $G^{\prime}$ and $G^{\prime \prime}$ dependencies cross each other. Relaxation times at other temperatures are then derived using $\tau(T)=\tau\left(T_{\text {ref }}\right)+\log a_{T}$.

\section{Results and discussion}

Figure 2 depicts the SAXS intensity distributions for the samples investigated. It is noted that the presence of carbosilane units in the 1,2-polybutadiene based core of the LS samples provides the necessary electron density contrast for SAXS measurements. It is evident that all three samples measured, namely LS2, LS3 and LS4, exhibit the identifying signature of liquid-like order, i.e., a weak broad primary peak in the scattered intensity (at a value of the scattering wave vector $q_{\text {peak }}$ ), accompanied by a weaker and broader secondary peak at a distance roughly $\sqrt{3} q_{\text {peak }}$. Note that the primary peak position moves to lower values of the scattering wave vector and the peak looses intensity as the arm molecular weight is increased; eventually, for the samples LS5 and LS6, the primary peak position could not be detected by SAXS. From the peak intensity position, the distances between the nearest neighbouring star centers were calculated by considering that the formed liquid-like structure is controlled by two-body correlations. In that case, these distances are 


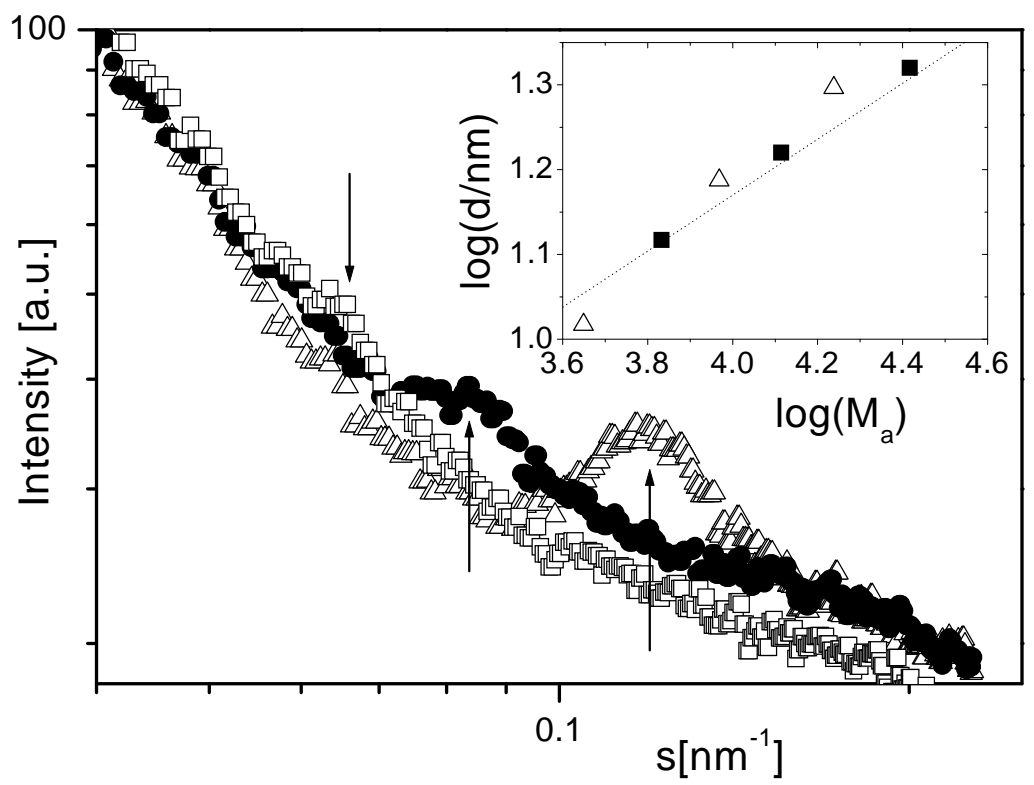

Figure 2. SAXS intensity distribution from measurements with the LS2 $(\triangle)$, LS3 $(\bullet)$ and LS4 ( $\square$ ) irregular multiarm star melt samples, indicating the weak liquid-like ordering. Arrows show the position of the primary peak $s_{\text {peak }}$ which corresponds to the characteristic length scale of the ordered structure. Inset: The dependence of the characteristic distance between neighbouring star "centers", $d=1.23 / s_{\text {peak }}$, on the arm molecular weigh for LS $(\triangle)$ and regular multiarm stars with $f=128$ arms ( $)$ from [10]. The dotted line denotes the slope of $1 / 3$ (see text).

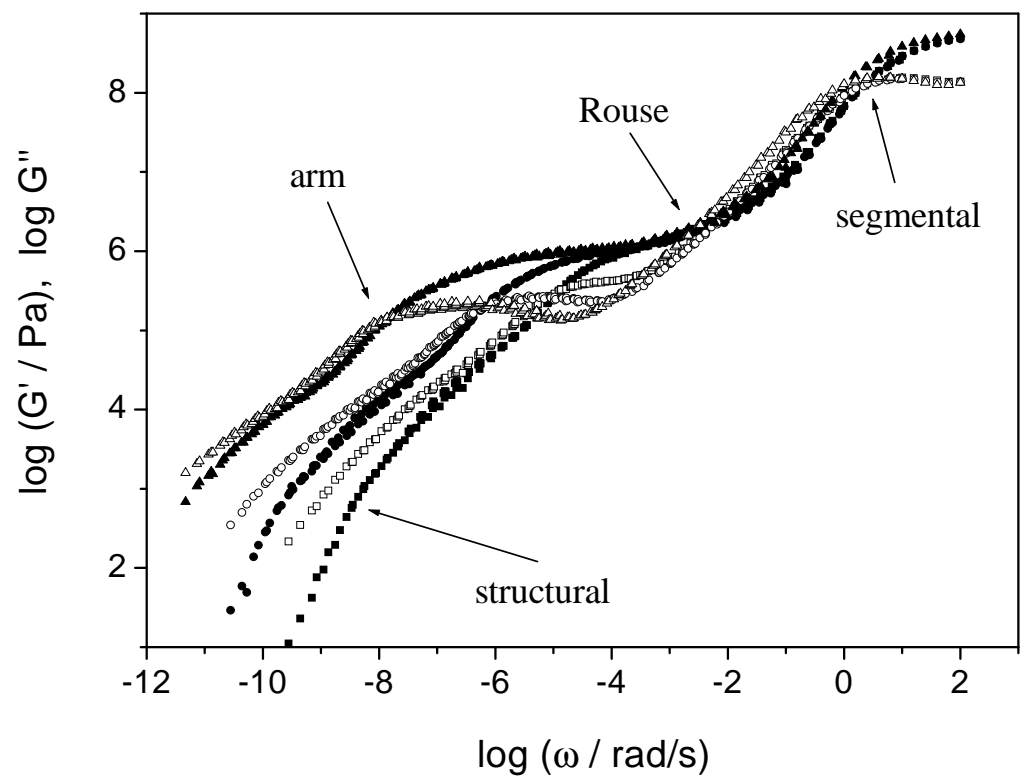

Figure 3. Dynamic frequency sweeps of stars LS2 (squares), LS3 (circles) and LS4 (up triangles) with reference temperature $T_{\text {ref }}=176 \mathrm{~K}$. Open symbols refer to $G^{\prime \prime}$ and closed symbols refer to $G^{\prime}$. Arrows indicate (from right to left) segmental, Rouse-like, arm and slow structural relaxation modes. 


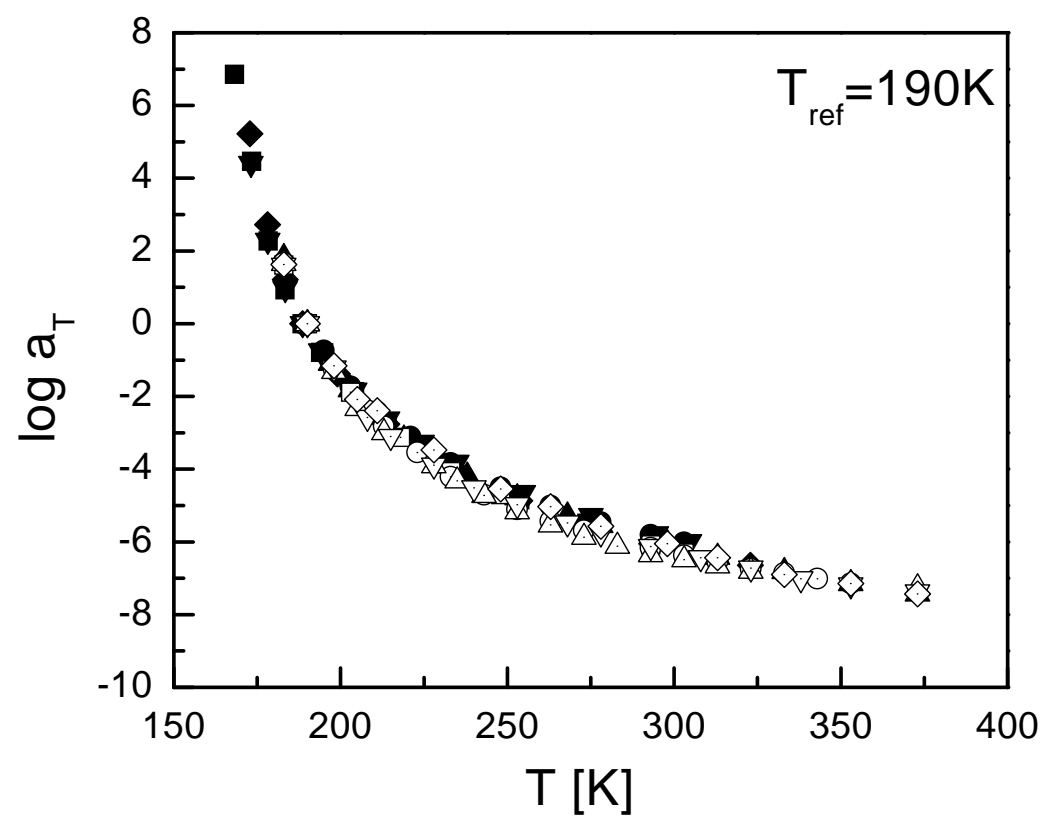

Figure 4. Temperature dependence of the frequency shift factors for $T_{\text {ref }}=190 \mathrm{~K}$ and various stars: Closed symbols refer to regular multiarm stars with 64 and 128 arms, and open symbols refer to the five irregular multiarm stars, namely LS2, LS3, LS4, LS5 and LS6.

given by $d \approx 1.23 / s_{\text {peak }}$ with $s_{\text {peak }}=q_{\text {peak }} / 2 \pi$, which for LS2, LS3 and LS4 amounts to $10.4,15.4$ and $19.8 \mathrm{~nm}$, respectively. The inset in figure 2 shows the dependence of $d$ on the arm molecular weight. In this plot, respective SAXS data from regular stars with $f=128$ are also included for comparison. The dotted line through the data has a slope of 0.33 , representative of $d \sim M_{a}^{1 / 3}$, typical for a cubic arrangement. Although one could argue that the present SAXS data slightly deviate from this relationship, the information available is not sufficient to support such a statement. More data with a large variety of (yet unavailable) stars would be needed to tackle this interesting point, which, if indeed true, may relate to the internal structural differences between regular and irregular multiarm stars.

Typical results of the dynamic response of the LS stars melts, determined by means of the rheological measurements, are shown in figure 3, which depicts the frequency dependence of the storage and loss moduli, $G^{\prime}$ and $G^{\prime \prime}$, respectively. In order to obtain the complete information on the material's response, from the highfrequency glass region to the low-frequency liquid region, measurements at different temperatures were combined into master curves in figure 3, by shifting all data along the frequency axis, according to the time-temperature superposition principle. Interestingly, all star 1,4-polybutadienes studied irrespectively of functionality and regularity (including the LS samples of this work) are found to exhibit the same thermorheologically simple behaviour, as indicated in figure 4, which shows the temperature dependence of the frequency shift factor $\alpha_{T}$. The well known WLF expression $\log \alpha_{T}=-c_{1}\left(T-T_{\text {ref }}\right) /\left(c_{2}+T-T_{\text {ref }}\right)$ [17] represents all data well with 


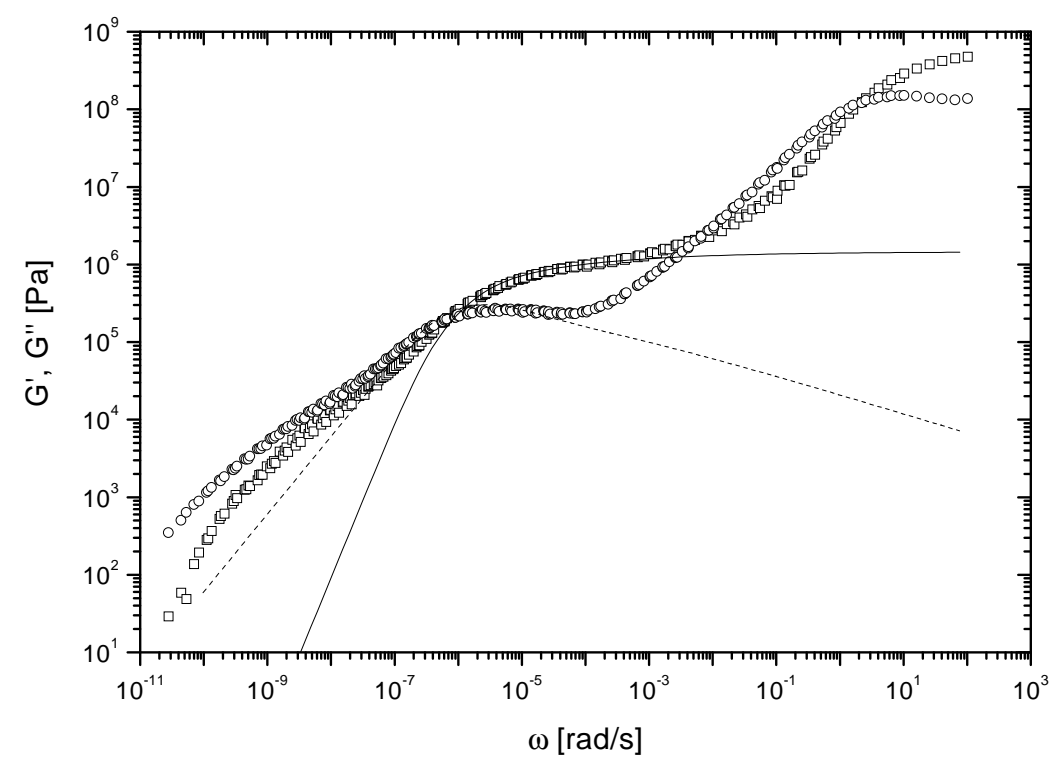

Figure 5. Comparison of the frequency spectra of LS2 with $T_{\text {ref }}=176 \mathrm{~K}$ with the theory of Milner and McLeish (solid curve for $G^{\prime}$ and dotted curve for $G^{\prime \prime}$ ) for the arm relaxation process.

$T_{\text {ref }}=190 \mathrm{~K}$ and fitted values $c_{1} \approx 12$ and $c_{2} \approx 50 \mathrm{~K}$, suggesting a universality in behaviour.

Starting from the higher frequencies of the master curves in figure 3, we note the glass transition region (extending up to the crossover frequency $\omega_{s}$ ), the Rouse-like transition regime $\left(\omega_{e}\right)$, the rubbery plateau $\left(\omega_{R}\right)$ and the terminal region. Note that the plateau modulus $G_{N}^{0}$ has the same value for the three LS samples in figure 3, as expected, and, moreover, it is nearly identical with that of the regular multiarm star polymers with 64 and 128 arms (as well as lower functionality entangled star polymers), yielding a value of the entanglement molecular weight $M_{e}=\rho R T / G_{N}^{0}$ of about $1850 \mathrm{~g} / \mathrm{mol}$, in accord with literature values for 1,4-polybutadiene [17]. Thus, the partial stretching of the arms in the near-core region due to high functionality and the differences in internal structure do not seem to affect $\mathrm{M}_{e}$ appreciably, within the resolution of the experimental techniques used.

The terminal region is characterized by the two-step decay [18], in sharp contrast to the single terminal relaxation processes of the low functionality stars, linear homopolymers or colloidal hard spheres, but in agreement with the regular multiarm stars. The faster one of the two relaxations in the terminal region $\left(\omega_{R}\right)$ is due to the star arm relaxation, as already established for regular stars of varying functionality $[10,11]$. In addition, this relaxation mode can be well described by the recent theory of Milner and McLeish for the arm relaxation, using the concept of dynamic dilution with the appropriate scaling of entanglement length, and incorporating the effects of higher Rouse modes on arm retraction [19]. This theory, developed in the framework of the tube model, has been able to quantitatively capture the arm relaxation of stars of different chemistry and functionality [14]. Its success with the irregular stars is demonstrated in figure 5 . Note that this theory uses as parameters only the 
entanglement molecular weight $M_{e}$, the respective plateau modulus $G_{N}^{0}$, and the (Rouse) relaxation time of an entanglement segment $\tau_{e}$, which are determined from the data. The complex viscoelastic modulus $G^{*}(\omega)$ is obtained from the expression:

$$
G^{*}(\omega)=(x+1) G_{N}^{0} \int_{0}^{1} \mathrm{~d} s(1-s)^{x}\left[\frac{\mathrm{i} \omega \tau(s)}{1+\mathrm{i} \omega \tau(s)}\right]
$$

where $s$ is the relaxed fraction of the arm. The total arm relaxation time

$$
\tau(s)=\left(\frac{\mathrm{e}^{-U_{\text {eff }}(s)}}{\tau_{\text {early }}(s)}+\frac{1}{\tau_{\text {activated }}(s)}\right)^{-1}
$$

incorporates an early fast diffusion of the free end of the arm $\left(\tau_{\text {early }}\right)$ and an activated arm retraction ( $\tau_{\text {activated }}$ ), and depends on $\tau_{e}$ and on the number of entanglements per arm; the latter is reduced by the dynamic dilution effect as $M_{e}(s)=M_{e} /(1-s)^{x}$, with $x=4 / 3$ [20]. From the results in figure 5, the assignment of the faster terminal process to arm relaxation is confirmed.

Figure 6 represents the dependence of the arm relaxation time under isofrictional conditions (normalized to the segmental time) $\tau_{a} / \tau_{s}$ on the arm degree of polymerization, $N_{a}$ (a), or alternatively on the number of entanglements, $M_{a} / M_{e}$ (b), for a variety of star polymers with functionality ranging from 4 to 270 , regular and irregular. The universal validity of this type of plot for all systems is noteworthy. It is also important to point out that these experimental results are in excellent agreement with simulation results $[10,11])$.

The slow relaxation process $\left(\omega_{c}\right)$ in figure 3 relates to the topological heterogeneity of the LS stars, yielding to distinct spatial correlations, as demonstrated in figure 2. Here, despite the non-spherical core, the very high arm number leads probably to a large monomer density around the star centers of mass and eventually results in the observed liquid-like order on the macromolecular scale. This type of structure is related to the excluded volume interaction between compact but deformable macromolecular elements in a dense system. Evidence from experiments and simulations with regular multiarm stars (with $f=128$ ) $[9,10,11,14]$ indicates that the slow process can be attributed to translational cooperative rearrangements of stars (on macromolecular scale) within the ordered state. These rearrangements are of the same character as these suggested for the cooperative rearrangements in low molecular liquids [21]. Note that because of the presence of the slow relaxation, the zero shear viscosity $\eta_{0}$ of multiarm stars is not independent of the functionality $f$, as in the case of low- $f$ stars [22].

Recently, a mean-field scaling theory was proposed to account for the slow mode. It considers an activated process involving a partial disentanglement of the interpenetrating stars followed by a displacement of a star in a neighbouring 'cell', a distance of its size apart, a process controlled by the free energy of the corona elastic deformation (arm stretching). The net result of this analysis suggests the following scaling 


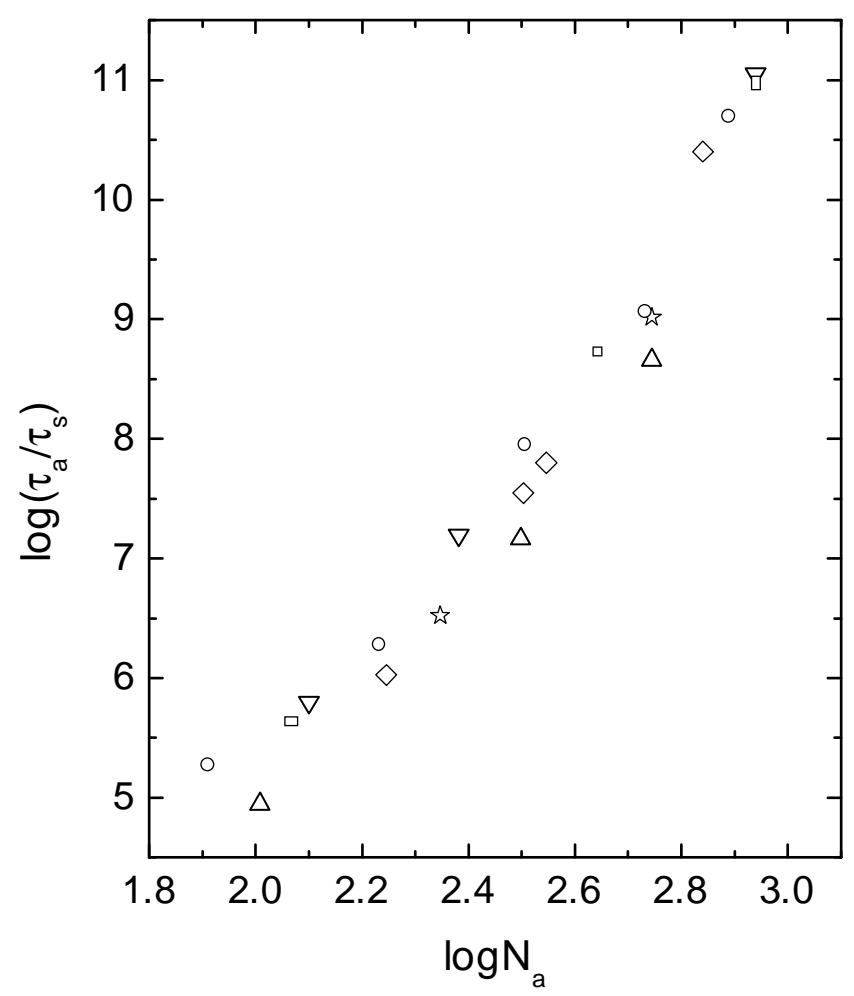

(a)

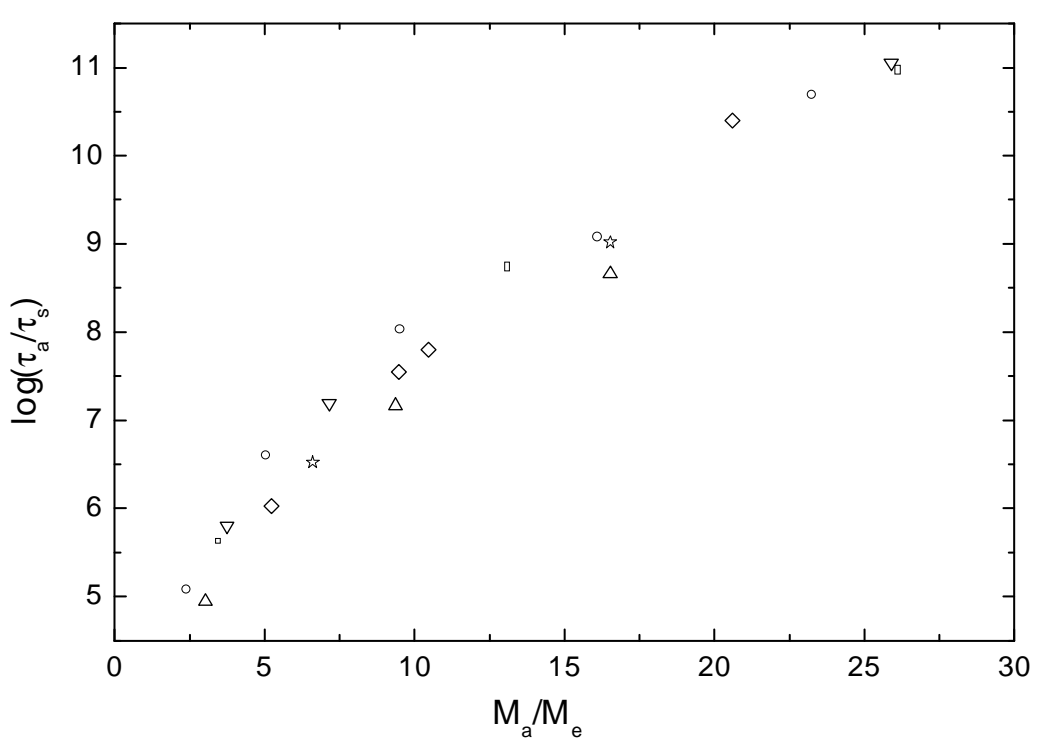

(b)

Figure 6. Isofrictional arm relaxation times $\left(\tau_{a} / \tau_{s}\right)$ against the arm degree of polymerization $\left(N_{a}\right)$, (a), or the number of entanglements $\left(M_{a} / M_{e}\right)$, (b), for the irregular star LS samples (o); for comparison respective data from regular polybutadiene stars with $f=128(\nabla), f=64(\square), f=32(\diamond), f=18(\triangle)$ and $f=4$ $(\star)$ are also shown. 


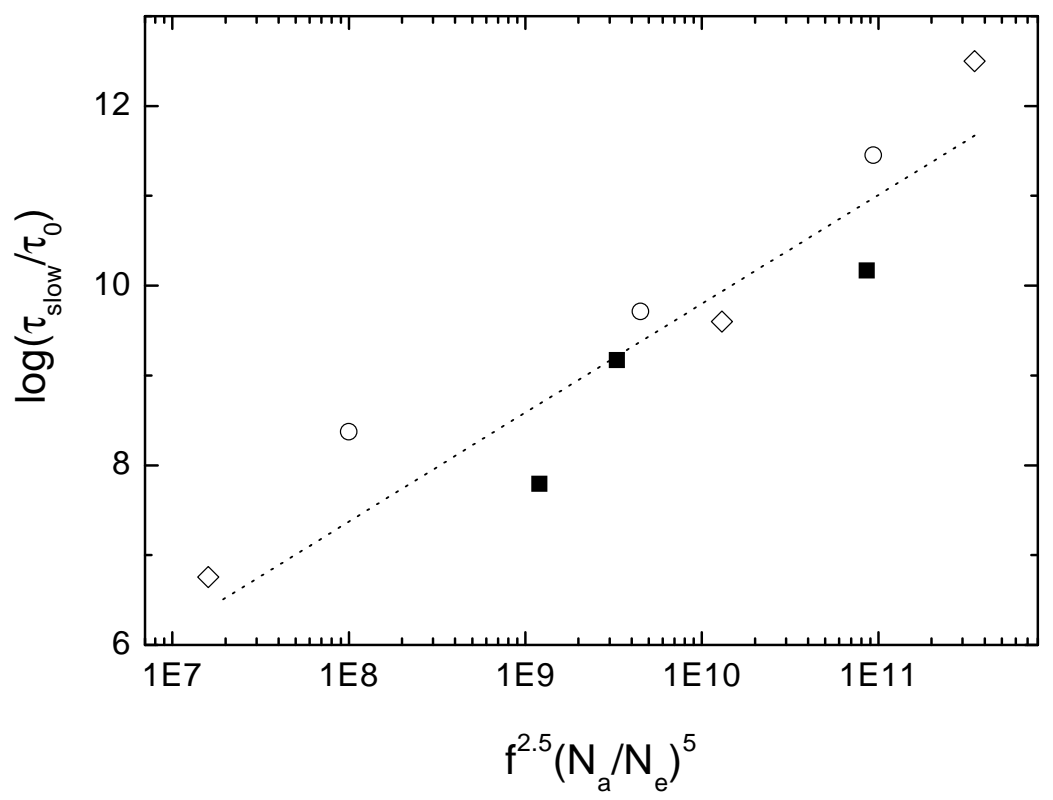

Figure 7. Normalized slow relaxation time (to the segmental time) $\tau_{\text {slow }} / \tau_{s}$ against $f^{2.5}\left(N_{a} / N_{e}\right)^{5}$ for irregular multiarm stars $(f=270)$ LS (o); for comparison, respective data from regular multiarm stars with functionality $f=64$ $(\diamond)$ and $f=128(\boldsymbol{\square})$, are also shown. The dotted line serves as a guide to the eye.

relation for the structural time $\tau_{\text {slow }}[14]$ :

$$
\frac{\tau_{\text {slow }}}{\tau_{s}} \sim \alpha^{-1 / 3} f^{11 / 9} N_{a}^{26 / 9} N_{e}^{-1} \exp \left[\frac{X_{1}}{\alpha} \frac{f^{5 / 3}}{N_{a}^{1 / 3}}+X_{2} \alpha^{2} \frac{N_{a}^{11 / 3}}{N_{e}^{3} f^{4 / 3}}\right],
$$

where $\alpha=\left(a^{2} v^{-2 / 3}\right)$ and $a$ is the monomer size, and $X_{1}$ and $X_{2}$ are unspecified numerical constants. The main outcome is the strong dependence of the structural relaxation on both functionality and arm molecular weight, in qualitative agreement with the experimental findings from the stars for which the slow process could be detected ( $f=64$ and 128), as well as with the simulations for stars up to $64 \mathrm{arms}$ $[10,11]$. For these systems, the extracted slow times were found to scale approximately with arm functionality and molecular weight as $\tau_{\text {slow }} / \tau_{s} \sim f^{2.5} N_{a}^{5}$. Actually, figure 7 depicts $\tau_{\text {slow }} / \tau_{s}$ against $f^{2.5}\left(N_{a} / N_{e}\right)^{5}$ for both regular $(f=64,128)$ and the irregular multiarm star polymers; it is apparent that the behaviour of the stars is rather universal with respect to their structural relaxation as well. The qualitative agreement of the theoretical prediction (strong $f$ and $N_{a}$ dependence) with the data is satisfactory, and was obtained using typical values for the numerical constants $X_{1}=0.0040$ and $X_{2}=0.0075$.

Simulations of comb shaped macromolecules in dense systems, reported elsewhere [23], indicate that the dynamics of such polymers having comparable lengths of the backbone and of the side chains are similar to the behaviour of stars because in both cases the slowest relaxation is controlled by the translational motion of the 
compact macromolecules. This can be considered as confirmed by the experimental results presented here. The simulation has further shown that a cross-over to the mechanism controlled by the orientation relaxation takes place when the length of the backbone starts to considerably exceed the length of side chains (arms). Such a behaviour has also been experimentally observed but for polymers with a large persistence length and the arms much shorter than the backbone length [23].

\section{Conclusions}

The investigation of melts of irregular highly branched star 1,4-polybutadienes with about 270 arms revealed striking similarities to their regular counterparts of functionality up to 128. Despite their difference in internal structure, these polymers exhibit liquid-like ordering resulting from their heterogeneous monomer density distribution and the related macromolecular excluded volume effects. In addition, their low-frequency dynamics is characterized by a dual viscoelastic relaxation, consisting of a fast arm relaxation and slow structural relaxation processes. It is concluded that the behaviour of such highly branched macromolecular objects is independent of the details of the core structure as long as the global shape of the compact objects does not deviate considerably from a spherical one.

\section{Acknowledgements}

The assistance of M.Kapnistos is gratefully acknowledged. Partial support has been received by the E.U. (grant HPRN-CT-2000-00017).

\section{References}

1. Vlassopoulos D., Fytas G., Pakula T., Roovers J. // J. Phys.: Condensed Matter, 2001, vol. 13, p. R855.

2. Likos C.N. // Physics Reports, 2001, vol. 348, p. 267.

3. Grest G.S., Huang J.S., Fetters L.J., Richter D. // Adv. Chem. Phys., 1996, vol. XCIV, p. 67.

4. Seghrouchni R., Petekidis G., Vlassopoulos D., Fytas G., Semenov A.N., Roovers J., Fleischer G. // Europhys. Lett., 1998, vol. 42, p. 271.

5. Roovers J., Zhou L.L., Toporowski P.W., van der Zwan P.W., Iatrou H., Hadjichristidis N. // Macromolecules, 1993, vol. 26, p. 4324.

6. Daoud M., Cotton J.B. // J. Phys. (Paris), 1982, vol. 43, p. 831.

7. Richter D., Jucknischke O., Willner L., Fetters L.J., Lin M., Huang J.S., Roovers J., Toporowski P.M., Zhou L.L. // J. Phys. (Paris), IV Suppl., 1993, vol. C8, p. 3.

8. Witten T.A., Pincus P.A., Cates M.E. // Europhys. Lett., 1986, vol. 2, p. 137.

9. Vlassopoulos D., Pakula T., Fytas G., Roovers J., Karatasos K., Hadjichristidis N. // Europhys. Lett., 1997, vol. 39, p. 617.

10. Pakula T., Vlassopoulos D., Fytas G., Roovers J. // Macromolecules, 1998, vol. 31, p. 8931.

11. Pakula T. // Comput. Theor. Polymer Science, 1998, vol. 8, p. 21.

12. Semenov A.N., Vlassopoulos D., Fytas G., Vlachos G., Fleischer G., Roovers J. // Langmuir, 1999, vol. 15, p. 358. 
13. Kapnistos M., Vlassopoulos D., Fytas G., Mortensen K., Fleischer G., Roovers J. // Phys. Rev. Lett., 2000, vol. 85, p. 4072.

14. Kapnistos M., Semenov A.N., Vlassopoulos D., Roovers J. // J. Chem. Phys., 1999, vol. 111, p. 1753.

15. Roovers J., Toporowski P., Martin J. // Macromolecules, 1989, vol. 22, p. 1897.

16. Loppinet B., Stiakakis E., Vlassopoulos D., Fytas G., Roovers J. // Macromolecules, 2001, vol. 34, p. 8216.

17. Ferry J.D. Viscoelastic Properties of Polymers. New York, Wiley, 1980.

18. Roovers J. // J. Non-Crystalline Solids, 1991, vol. 131-133, p. 793.

19. Milner S.T., McLeish T.C.B. // Macromolecules, 1997, vol. 30, p. 2159.

20. Colby R.H., Rubinstein M. // Macromolecules, 1990, vol. 23, p. 2753.

21. Pakula T. // J. Mol. Liquids, 2000, vol. 86, p.109.

22. Fetters L.J., Kiss A.D., Pearson D.S., Quack G.F., Vitus F.J. // Macromolecules, 1993, vol. 26, p. 4324.

23. Pakula T., Harre K. // Comput. Theor. Polym. Sci., 2000, vol. 10, p. 197.

\title{
Структура і динаміка нерегулярних багатоланцюгових зіркових полімерів
}

\author{
Д.Влассопулос ${ }^{1}$, Т.Пакула ${ }^{2}$, Дж.Руверс ${ }^{3}$ \\ 1 Фонд досліджень та технології - Геллас \\ Інститут вивчення електронної структури та лазерів, \\ 71110 Геракліон, Кріт, Греція \\ 2 Інститут ім. Макса Планка з дослідження полімерів, \\ 55021 Майнц, Німеччина \\ 3 Національна рада з наукових досліджень, \\ Інститут хімічних процесів та природозберігаючих технологій, \\ Оттава, Онтаріо K1A0R6, Канада
}

\section{Отримано 1 жовтня 2001 р.}

Досліджено властивості розчинення сильно розгалужених зіркових полімерів із основою 1,2-полібутадієну і близько 270 гілок 1,4-полібутадієну змінного розміру, використовуючи рентгенівське випромінювання при малих кутах і динамічні реологічні вимірювання у границі лінійної в'язкоеластичності. Нехтуючи різницею внутрішньої структури, порівняно із періодичними зірками із 128 відгалуженнями і сферичною деревоподібною основою, ці полімери мають ту ж рису: рідиноподібне впорядкування, що є результатом специфічного розподілу густини мономерів. Це приводить до кінцевої в'язкоеластичної релаксації, що складається із швидкої релаксації відгалужень і повільної структурної релаксації. Обидві моди кількісно узгоджуються із характерною поведінкою, припускаючи універсальність поведінки сильнорозгалужених макромолекулярних об'єктів.

Ключові слова: зіркові полімери, структура, реологія, лінійна в'язкоеластичність, релаксаційні процеси, динаміка

PACS: $61.25 . \mathrm{Hq}$, 83.10.Nn, 81.05. Lg 